\title{
Molecular characterisation of the tick Rhipicephalus microplus in Malaysia: new insights into the cryptic diversity and distinct genetic assemblages throughout the world
}

Van Lun Low ${ }^{1 *}$, Sun Tee Tay², Kai Ling Kho², Fui Xian Koh², Tiong Kai Tan³ ${ }^{3}$ Yvonne Ai Lian Lim³ ${ }^{3}$ Bee Lee Ong ${ }^{4}$, Chandrawathani Panchadcharam ${ }^{5}$, Yusoff Norma-Rashid ${ }^{1}$ and Mohd Sofian-Azirun ${ }^{1}$

\begin{abstract}
Background: The morphotaxonomy of Rhipicephalus microplus complex has been challenged in the last few years and prompted many biologists to adopt a DNA-based method for distinguishing the members of this group. In the present study, we used a mitochondrial DNA analysis to characterise the genetic assemblages, population structure and dispersal pattern of $R$. microplus from Southeast Asia, the region where the species originated.

Methods: A phylogeographic analysis inferred from the $16 \mathrm{~S}$ rRNA and cytochrome oxidase subunit I (COI) genes was performed with five populations of R. microplus collected from cattle in Malaysia. Malaysian R. microplus sequences were compared with existing COI and 16S rRNA haplotypes reported globally in NCBI GenBank.
\end{abstract}

Results: A total of seven and 12 unique haplotypes were recovered by the $16 \mathrm{~S}$ rRNA and COI genes, respectively. The concatenated sequences of both 16S rRNA and COI revealed 18 haplotypes. Haplotype network and phylogenetic analyses based on COI+16S rRNA sequences revealed four genetically divergent groups among Malaysian R. microplus. The significantly low genetic differentiation and high gene flow among Malaysian $R$. microplus populations supports the occurrence of genetic admixture. In a broader context, the 165 rRNA phylogenetic tree assigned all isolates of Malaysian R. microplus into the previously described African/the Americas assemblage. However, the $\mathrm{CO}$ phylogenetic tree provides higher resolution of $R$. microplus with the identification of three main assemblages: clade A sensu Burger et al. (2014) comprises ticks from Southeast Asia, the Americas and China; clade B sensu Burger et al. (2014) is restricted to ticks that originated from China; and clade C sensu Low et al. (2015) is a new genetic assemblage discovered in this study comprising ticks from India and Malaysia.

Conclusions: We conclude that the $R$. microplus complex consisting of at least five taxa: $R$. australis, $R$. annulatus, $R$. microplus clade A sensu Burger et al. (2014), R. microplus clade B sensu Burger et al. (2014) and the new taxon, $R$. microplus clade $C$ sensu Low et al. (2015). The use of COI as the standard genetic marker in discerning the genetic assemblages of $R$. microplus from a broad range of biogeographical regions is proposed.

Keywords: Rhipicephalus microplus, Cattle Tick, COI Gene, 165 rRNA Gene, Malaysia

\footnotetext{
* Correspondence: lucaslow24@gmail.com

${ }^{1}$ Institute of Biological Sciences, Faculty of Science, University of Malaya,

Kuala Lumpur, Malaysia

Full list of author information is available at the end of the article
} 


\section{Background}

The southern cattle tick, Rhipicephalus microplus (formerly Boophilus microplus), is the most notorious bloodfeeding ectoparasite of livestock, especially cattle. Over the years, the veterinary importance of $R$. microplus transmitting various pathogens has been acknowledged worldwide [1-7]. Additionally, the estimated annual losses associated with $R$. microplus are US\$ 2.5 billion throughout tropical and subtropical regions [8].

To date, the ticks of the $R$. microplus complex consisting of four taxa, namely $R$. australis, $R$. annulatus, $R$. microplus clade A sensu Burger et al. (2014) and $R$. microplus clade B sensu Burger et al. (2014). Nonetheless, the morphotaxonomy of $R$. microplus complex has been challenged in the last few years and remained difficult to morphologically differentiate these members [9]. Molecular characterisation is the alternate way to distinguish these closely related taxa, as well as other Rhipicephalus ticks [10].

The phylogeography of $R$. microplus has been wellstudied in many parts of the world using various molecular approaches, such as random amplified polymorphic DNA [11], restriction fragment length polymorphism [12] and microsatellite analyses [13, 14]. In 2009, Labruna et al. [15] used both mitochondrial genes (12S rRNA and $16 \mathrm{~S}$ rRNA) and microsatellite markers to charactesize the genetic assemblages of $R$. microplus from Australia, Asia, Africa and the Americas. The results showed three distinct clades - one comprising ticks from the Americas and Africa; another comprising ticks from Australia, Indonesia and New Caledonia; and one comprising ticks from India and Nepal. As a result, $R$. microplus ticks from Australia, Indonesia and New Caledonia have been reinstated as $R$. australis based on reproductive isolation and taxonomic evidence [16]. A more recent study discovered a new mitochondrial COI gene lineage that is restricted to ticks from China, suggesting the presence of cryptic species that is more closely related to $R$. annulatus [10]. Thus far, the current literature has documented two distinct mitochondrial COI gene assemblages of $R$. microplus, so called clade A sensu Burger et al. (2014) and clade B sensu Burger et al. (2014) [9].

There is a gap in knowledge concerning the genetic assemblages and population structure of $R$. microplus from Southeast Asia. Previous studies have genetically analysed ticks from Australia, the Americas and Africa but sampling was limited, with most countries represented by a single individual. Small sample size provides little support for intraspecific genetic diversity and phylogenetic inferences [17]. Therefore, further studies on the population structure of Southeast Asian R. microplus, including those of Malaysia, are warranted. Given the high resolution of mitochondria-encoded $16 \mathrm{~S}$ rRNA and COI genes reported in Rhipicephalus ticks [10, 15, 18], this study attempts to utilize these genes to reveal the hidden intraspecific genetic diversity and dispersal patterns of $R$. microplus for the first time in Malaysia. To infer the genetic assemblages of Malaysian $R$. microplus, sequences were compared with existing COI and 16S rRNA haplotypes reported globally in NCBI GenBank.

\section{Methods}

\section{Ethics statement}

All experiments were performed in accordance with relevant guidelines and regulations of the University of Malaya. The research protocols were regulated and approved by the University of Malaya. Prior to the commencement of the sample collection, permission was approved by the Department of Veterinary Services, Ministry of Agriculture and Agro-Based Industry, Malaysia (Reference Number: JPV/PSTT/100-8/1). This study did not involve endangered or protected species.

\section{Tick specimens}

Tick collection was conducted on 10 animal farms (each farm with 30-40 individual animals) in seven states in Peninsular Malaysia, namely Kelantan (Farm A, Tanah Merah district), Terengganu (Farm B, Hulu Terengganu district), Pahang (Farm C, Kuantan district and Farm D, Jerantut district), Johore (Farm E, Batu Pahat district), Negeri Sembilan (Farm F, Jelebu district and Farm G, Gemas district), Selangor (Farm H, Serdang district and Farm I, Kuala Langat district) and Kedah (Farm J, Pokok Sena district) (Fig. 1). Cattle were raised at Farm A - Farm E and Farm G - Farm I, whereas sheep, goats and swine were raised at Farm J, Farm F and Farm I, respectively.

Rhipicephalus microplus was preliminary identified and separated from the closely related species $R$. annulatus by a set of morphological features: (1) short and deeply concave internal margin of the first palp article, (2) presence of a small spur on the second coxa of females, (3) presence of a caudal appendage in males [19]. To differentiate $R$. microplus from $R$. australis, the critical morphological features were: (1) dorsal setae are short and slender, and medial alloscutal setae form clusters of 2-3 rows in females, (2) absence of a spur on the ventral surface of first palp article of males, (3) presence of several setae on the lateral margins of the ventral surface of the capitulum in males [16]. The species identity was further confirmed by the $16 \mathrm{~S}$ rRNA marker which can genetically separate the closely related species $R$. annulatus and $R$. australis $[10,15,16]$.

Rhipicephalus microplus ticks were identified from cattle on five farms (Farms B, C, D, G and H) with low to high frequencies (personal observations). The cattle ticks were collected from three imported cattle breeds: Brahman $(n=3)$, Friesian Sahiwal $(n=4)$ and Nellore $(n=17)$; and three local cross breeds of cattle: Kedah Kelantan 


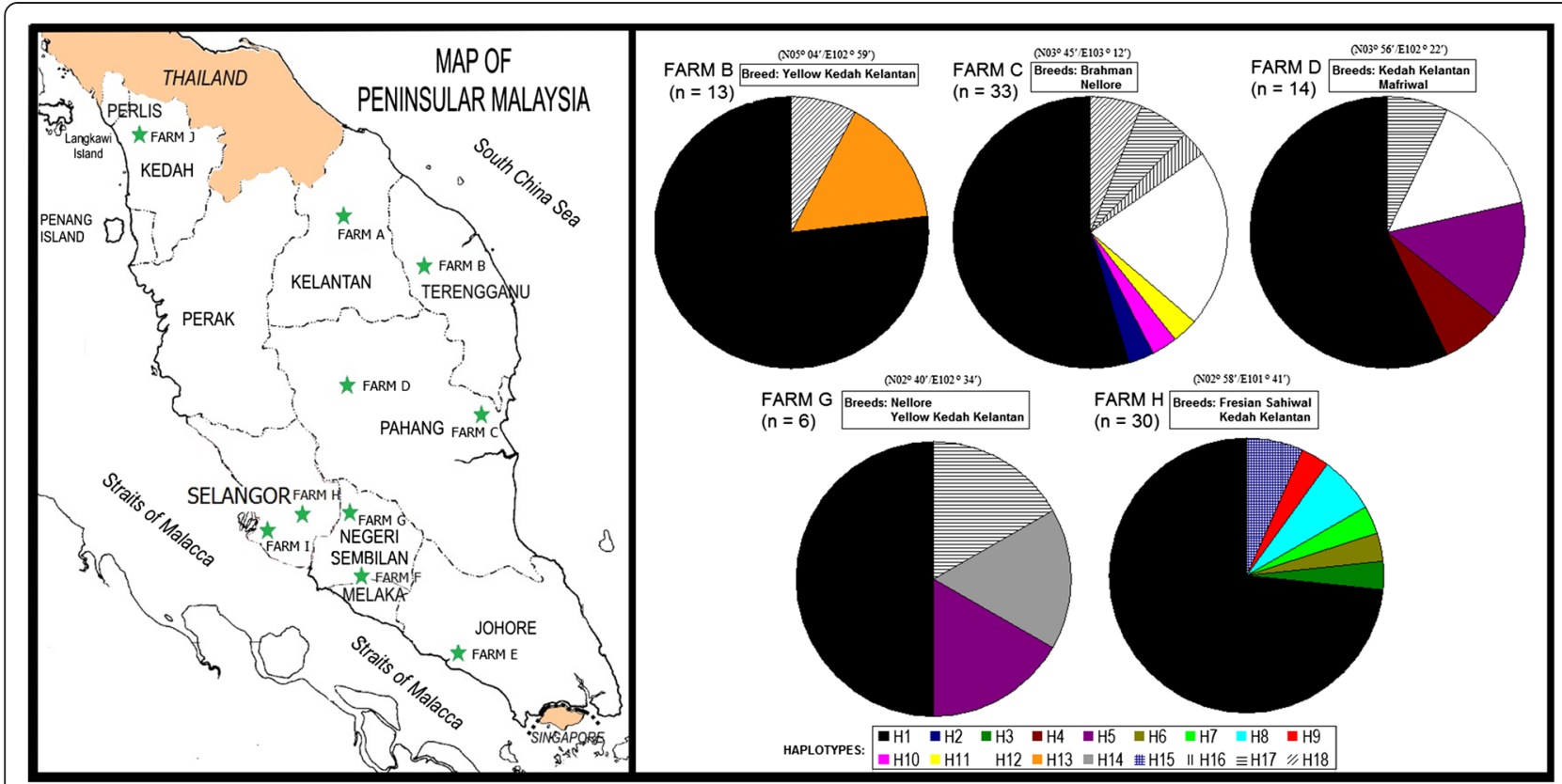

Fig. 1 Collection sites of $R$. microplus and haplotype distribution ( $\mathrm{H} 1-\mathrm{H} 18)$ of $\mathrm{COI}+16 \mathrm{~S}$ rRNA sequences in Peninsular Malaysia

$(n=27)$, Mafriwal $(n=1)$ and Yellow Kedah Kelantan $(n=13)$. All $R$. microplus collected at Farm B $(n=13)$, Farm D $(n=14)$ and Farm G $(n=6)$ were used in DNA analyses, whereas randomly selected individuals from a larger sample from Farm C $(n=33$, of 106) and Farm $\mathrm{H}$ $(n=30$, of 249$)$ were analysed. A total of 96 individual ticks from five farms were sequenced and analysed in this study (Table 1). The voucher specimens were deposited at the Museum of Zoology, University of Malaya, Malaysia.

\section{Polymerase chain reaction (PCR)}

Rhipicephalus microplus DNA was extracted from each specimen $(n=96)$, using QIAamp DNA Mini Kit (Qiagen, Hilden, Germany). The amplifications of the mitochondrial COI and 16S rRNA genes were performed in a final volume of $50 \mu \mathrm{L}$ containing 50-100 ng genomic DNA, $25 \mu \mathrm{L}$ of ExPrime Taq Master Mix (GENETBIO Inc., Daejeon, South Korea) and 10 pmol of each forward and reverse primer. PCR was conducted with an Applied Biosystems Veriti 96-Well Thermal Cycler (Applied Biosystems, Inc., Foster City, CA, USA).

Low amplification success rates $(<50 \%)$ were found from three pairs of COI primers [20-22], a common problem in the recovery of COI fragment from tick specimens [23]. To solve this issue, the COI of $R$. microplus was amplified using nested PCR in the present study. The first PCR was performed using the cycling parameters and primer pairs ( $\operatorname{cox} 1 \mathrm{~F}$ and $\operatorname{cox} 1 \mathrm{R})$ from Chitimia et al. [22]. For the nested PCR amplification, $1 \mu \mathrm{L}$ of the product from the first amplification was used with the primers C1-J-1718 and C1-N-2329 from Shao et al. [21] in a $50 \mu \mathrm{L}$ reaction mixture. The modified PCR cycling parameters were: $94{ }^{\circ} \mathrm{C}$ for $5 \mathrm{~min}, 35$ cycles of $94{ }^{\circ} \mathrm{C}$ for $30 \mathrm{~s}, 59{ }^{\circ} \mathrm{C}$ for $1 \mathrm{~min}$ and $72{ }^{\circ} \mathrm{C}$ for $1 \mathrm{~min}$; and $72{ }^{\circ} \mathrm{C}$ for $10 \mathrm{~min}$. For the $16 \mathrm{~S}$ rRNA gene, PCR amplification was performed using the primer pairs $16 \mathrm{~S}$ $\mathrm{F}$ and $16 \mathrm{~S}-\mathrm{R} 1$ and PCR cycling parameters described in Lv et al. [20]. A negative control was included in each PCR run.

\section{DNA sequencing and data analyses}

Purified PCR products were sent to a commercial company for DNA sequencing in forward and reverse directions. Sequence data were analysed and edited using Sequence Scanner 1.0 (Applied Biosystems, Foster City, CA, USA) and BioEdit 7.0.9.0 [24]. The partition homogeneity test was conducted using PAUP 4.0b10 [25]. No significant differences were found among separate gene regions $(P=0.88)$; hence data were concatenated for relevant analyses. The aligned COI and 16S rRNA sequences comprised 625 bp and $399 \mathrm{bp}$, respectively. The multiple sequences of both COI and 16S rRNA were concatenated to yield a total length of $1024 \mathrm{bp}$. Sequence alignment of $R$. microplus haplotypes $(\mathrm{H} 1-\mathrm{H} 18)$ based on COI + $16 \mathrm{~S}$ rRNA genes is shown in Additional file 1: Figure S1. Distinct haplotypes of COI (KM246866-KM246877) and 16S rRNA (KM246878KM246884) were deposited in NCBI GenBank.

A median-joining analysis implemented in the program SplitsTree4 4.13.1 [26] was used for the intraspecific analysis of the evolutionary relationships among haplotypes. Uncorrected (p) pairwise genetic distances were calculated 
Table 1 Sample sizes (N/n), haplotype diversity (Hd), nucleotide diversity (pi) and number of haplotypes (h) based on COI, 16S rRNA and $\mathrm{COI}+16 \mathrm{~S}$ rRNA sequences of $R$. microplus populations in Malaysia

\begin{tabular}{|c|c|c|c|c|c|c|c|c|c|c|c|}
\hline \multirow[t]{2}{*}{ Farm } & \multirow[t]{2}{*}{ N } & \multirow[t]{2}{*}{$n$} & \multicolumn{3}{|l|}{$\mathrm{COl}$} & \multicolumn{3}{|c|}{$16 \mathrm{~S}$ rRNA } & \multicolumn{3}{|c|}{$\mathrm{COI}+16 \mathrm{~S}$ rRNA } \\
\hline & & & $\mathrm{Hd}$ & pi & $\mathrm{h}$ & $\mathrm{Hd}$ & $\mathrm{Pi}$ & $\mathrm{h}$ & $\mathrm{Hd}$ & $\mathrm{pi}$ & $\mathrm{h}$ \\
\hline $\bar{B}$ & 13 & 13 & 0.1539 & 0.0010 & 2 & 0.2821 & 0.0007 & 2 & 0.4103 & 0.0009 & $3(\mathrm{H} 1, \mathrm{H} 13, \mathrm{H} 18)$ \\
\hline C & 106 & 33 & 0.6042 & 0.0023 & 5 & 0.1761 & 0.0005 & 4 & 0.6667 & 0.0016 & $8(\mathrm{H} 1, \mathrm{H} 2, \mathrm{H} 10, \mathrm{H} 11, \mathrm{H} 12, \mathrm{H} 16, \mathrm{H} 17, \mathrm{H} 18)$ \\
\hline D & 14 & 14 & 0.6703 & 0.0296 & 5 & 0.0000 & 0.0000 & 1 & 0.6703 & 0.0016 & $5(\mathrm{H} 1, \mathrm{H} 4, \mathrm{H} 5, \mathrm{H} 12, \mathrm{H} 17)$ \\
\hline G & 6 & 6 & 0.8000 & 0.0337 & 4 & 0.3333 & 0.0008 & 2 & 0.8000 & 0.0209 & $4(\mathrm{H} 1, \mathrm{H} 5, \mathrm{H} 14, \mathrm{H} 17)$ \\
\hline $\mathrm{H}$ & 249 & 30 & 0.3632 & 0.0148 & 6 & 0.1862 & 0.0005 & 2 & 0.4644 & 0.0092 & $7(\mathrm{H} 1, \mathrm{H} 3, \mathrm{H} 6, \mathrm{H} 7, \mathrm{H} 8, \mathrm{H} 9, \mathrm{H} 15)$ \\
\hline Total & 388 & 96 & 0.5123 & 0.0124 & 12 & 0.1787 & 0.0005 & 7 & 0.5875 & 0.0077 & $18(\mathrm{H} 1-\mathrm{H} 18)$ \\
\hline
\end{tabular}

$N=$ number of ticks collected; $n=$ number of ticks genotyped

using PAUP 4.0B10 [25] to assess the genetic divergence of $R$. microplus in both COI and 16S rRNA genes.

To assess the level of genetic differentiation, gene flow and genetic differentiation tests implemented in the program DnaSP 5.0 [27] were performed. Haplotype diversity (Hd), nucleotide diversity (pi), number of haplotypes (h), genetic differentiation $\left(\mathrm{F}_{\mathrm{ST}}\right)$ and gene flow $(\mathrm{Nm})$ values were determined. The levels of genetic differentiation are defined as $F_{S T}>0.25$ (great differentiation), 0.15 to 0.25 (moderate differentiation) and $F_{S T}<0.05$ (negligible differentiation) [28]. The levels of gene flow are defined as $\mathrm{Nm}>1$ (high gene flow), 0.25 to 0.99 (intermediate gene flow) and $\mathrm{Nm}<0.25$ (low gene flow) [29].

The distinct COI and 16S rRNA haplotypes identified in the Malaysian $R$. microplus ticks were aligned with all representative sequences of Rhipicephalus taxa available in NCBI GenBank. Hyalomma detritum was used as an outgroup for the construction of phylogenetic trees based on COI and 16S rRNA sequences. A neighbor-joining (NJ) phylogenetic tree [30] was plotted using MEGA5 [31]. The NJ bootstrap values were estimated using 1000 replicates with Kimura's two-parameter model of substitution (K2P distance) [32]. Gaps and missing data were eliminated. A maximum likelihood (ML) analysis was run in PhyML 3.0 [33], using a HKY85 model with parameters estimated by the program.

\section{Results}

\section{Haplotype and nucleotide analyses}

A total of seven, 12 and 18 unique haplotypes were identified based on the sequence variation of the $16 \mathrm{~S}$ rRNA, COI and COI + 16S rRNA genes, respectively, from 96 ticks collected from five farms in Peninsular Malaysia. The combined COI $+16 \mathrm{~S}$ rRNA dataset showed a greater haplotype diversity $(0.5875)$ than COI $(0.5123)$ or $16 \mathrm{~S}$ rRNA (0.1787) genes alone, whereas the COI gene showed greater nucleotide diversity $(0.0124)$ than the combined COI $+16 \mathrm{~S}$ rRNA (0.0077) dataset or $16 \mathrm{~S}$ rRNA (0.0005) alone (Table 1). Haplotype network analysis (COI + 16S rRNA) showed four distinct haplotype clusters among Malaysian populations but revealed a lack of clear separation by tick populations/geographical areas, indicating an overlap of the four genetically divergent groups of $R$. microplus. Haplotype $\mathrm{H} 1$ was the most widespread haplotype $(n=61)$ in all populations (Figs. 1 and 2). Notably, the H16, H17 and H18 haplotypes, which mainly originated from the Nellore breed, formed a single cluster (clade C), shown in Fig. 2. However, the association of these haplotypes with other cattle breeds was not obvious.

\section{Genetic distance, genetic differentiation and gene flow}

In the uncorrected " $\mathrm{p}$ " distance matrix, the COI gene indicated stronger resolving power (0.00-9.28 \%) compared with $16 \mathrm{~S}$ rRNA $(0.00-0.50 \%)$ (Table 2). The genetic distance of the representative COI $+16 \mathrm{~S}$ rRNA haplotypes of $R$. microplus ranged from 0.10 to $5.76 \%$ (Table 3). Overall, significant genetic differentiation was observed among all populations $(P<0.05)$. However, a relatively low level of genetic differentiation was found among the five tick populations. The majority of the population pairs showed low genetic differentiation. Moderate genetic differentiation $\left(F_{S T}=0.15\right)$, revealed by the COI and COI + 16S rRNA genes, was found between populations B and D. Additionally, high levels of gene flow were observed among tick populations as shown by the high $\mathrm{Nm}$ in the COI (36.92), 16S rRNA (12.47) and COI + 16S rRNA (35.59) genes (Table 4).

\section{Phylogenetic analyses}

$\mathrm{NJ}$ and ML analyses produced phylogenetic trees with the same topology but with different bootstrap support values (Figs. 2, 3 and 4). Only NJ trees were presented for the sequences of $16 \mathrm{~S}$ rRNA and COI.

The 18 haplotypes (H1-H18) generated from the concatenated COI and 16S rRNA sequences of Malaysian $R$. microplus were subjected to phylogenetic analyses. Rhipicephalus microplus generally comprises four main clades: clade A (H4-H7), clade B (H14-H15), clade C (H16-H18) and clade D (H1-H2, H8-H13). There was no bootstrap support for haplotype H3, which formed a single clade (Fig. 2). Similar to the results of the haplotype 


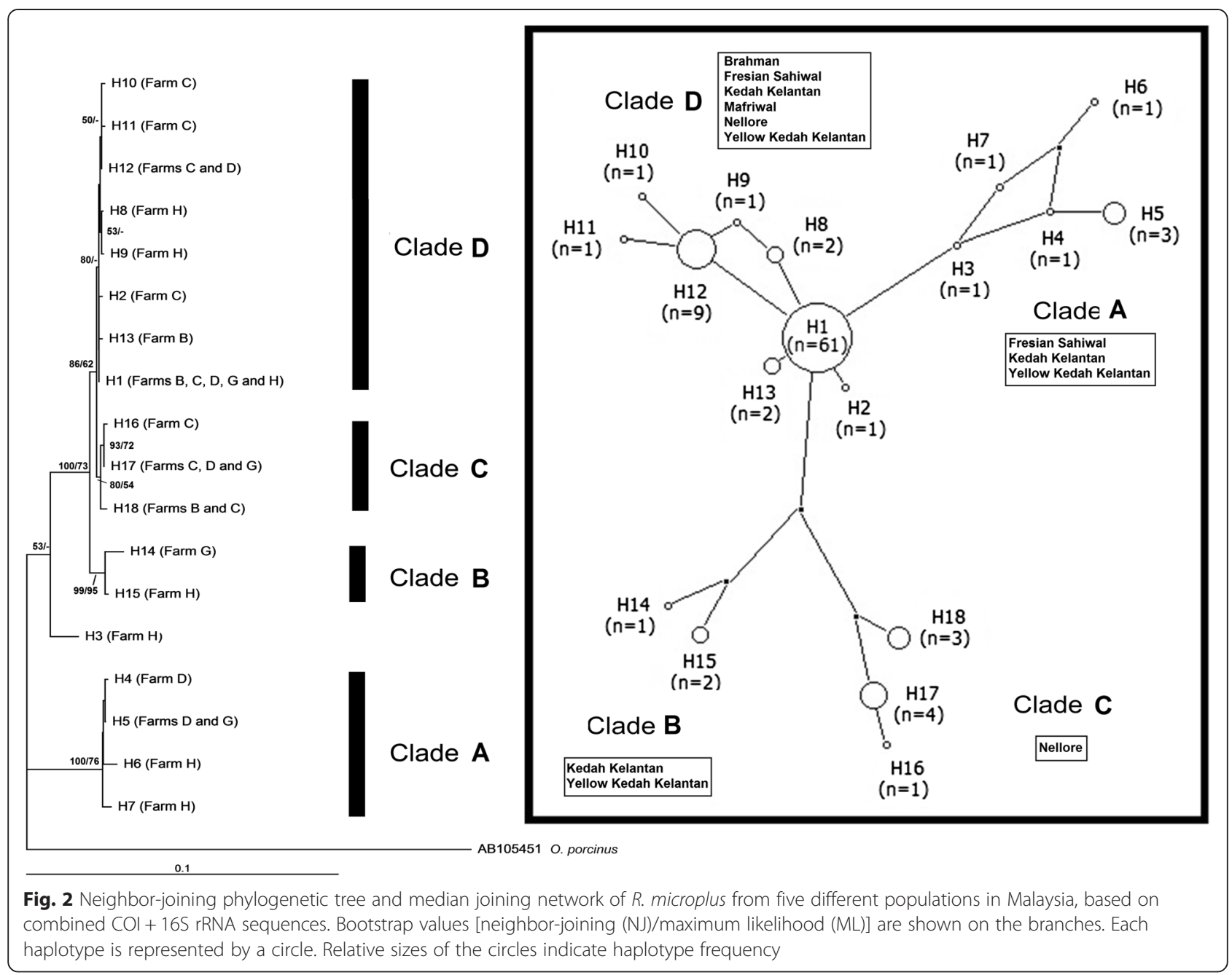

network analysis, clade $\mathrm{C}$ is associated with ticks collected from the Nellore breed.

The $16 \mathrm{~S}$ rRNA phylogenetic tree revealed two $R$. microplus genetic clades. One well-supported clade comprised $R$. microplus from China and India and was sister to $R$. annulatus. Rhipicephalus microplus from China was the basal member, forming a subclade with $R$. microplus from India. Rhipicephalus australis (formerly identified as $R$. microplus) from Australia, New Caledonia and Indonesia formed a well-supported clade. Rhipicephalus microplus from Malaysia, Japan, Africa (i.e., Mozambique, South Africa and Tanzania) and the Americas (i.e., Argentina, Bolivia, Brazil, Costa Rica, Paraquay, Peru and Uruguay) formed another clade (clade B) (Fig. 3).

The COI phylogenetic tree revealed three genetic clades of $R$. microplus. Clade A $[R$. microplus clade A sensu Burger et al. (2014)], the basal clade, comprised ticks from Southeast Asia (Cambodia and Malaysia), the Americas (Brazil and Panama) and China. Clade B $[R$. microplus clade B sensu Burger et al. (2014)], was restricted to ticks that originated from China. Clade $\mathrm{C}[R$. microplus clade C sensu Low et al. (2015) comprised ticks from India and Malaysia. Haplotype 12 from Malaysia formed a distinct clade with no bootstrap support; thus, we excluded this clade as a valid genetic assemblage. Rhipicephalus microplus clade A sensu Burger et al. (2014) showed a sister relationship to R. australis. By contrast, $R$. microplus clade B sensu Burger et al. (2014) is more closely related to $R$. annulatus, with which they formed a sister relationship (Fig. 4).

\section{Discussion}

In this study, we delineated the intraspecific genetic diversity and phylogeographical relationships of a major international pest of livestock, $R$. microplus, using $16 \mathrm{~S}$ rRNA and COI markers. The results clearly indicate the advantages of using the COI gene for providing sufficient power to resolve the evolutionary relationships of $R$. microplus. We, like Burger et al. [10] found that the COI sequences were more variable and informative than $16 \mathrm{~S}$ rRNA sequences. Exceptionally high levels of genetic variability were revealed by the COI gene. The intraspecific genetic 
Table 2 Percentage of uncorrected " $p$ " distance matrix between populations based on COI (upper right matrix) and 16S rRNA (lower left matrix) sequences of R. microplus in Malaysia

\begin{tabular}{llllll}
\hline & $B$ & $C$ & $D$ & $G$ & $H$ \\
\hline$B$ & - & $0.00-0.80$ & $0.00-8.48$ & $0.00-8.32$ & $0.00-8.64$ \\
C & $0.00-0.50$ & - & $0.00-8.64$ & $0.00-8.48$ & $0.00-9.12$ \\
$D$ & $0.00-0.25$ & $0.00-0.25$ & - & $0.00-8.80$ & $0.00-8.96$ \\
$G$ & $0.00-0.50$ & $0.00-0.50$ & $0.00-0.25$ & - & $0.00-9.28$ \\
$H$ & $0.00-0.50$ & $0.00-0.50$ & $0.00-0.25$ & $0.00-0.50$ & - \\
\hline
\end{tabular}

distance or haplotype frequency reported here are notably higher than previously described for $R$. appendiculatus, $R$. sanguineus sensu lato, $R$. guilhoni, $R$. pusillus, $R$. turanicus, $R$. muhsamae and $R$. bursa $[18,34,35]$. Furthermore, the two, and perhaps three, genetic assemblages inferred from Malaysian $R$. microplus are more genetically diverse than those reported from other regions of the world (Fig. 4).

Among the five studied populations, $R$. microplus from Farm $G$ was genetically diverse, as supported by the highest haplotype and nucleotide diversity based on COI, 16S rRNA and $\mathrm{COI}+16 \mathrm{~S}$ rRNA sequences (Table 1). As one of the farm management strategies in Malaysia, Farm $G$ acts as the 'weaner's park' and supplies weaned calves to other government farms (Farm A Farm E and Farm G - Farm I) that are owned by the Department of Veterinary Services (DVS), Malaysia. Hence, we suggest that Farm $G$ might be one of the sources for multiple introductions of $R$. microplus assemblages into other farms in Malaysia.
Table 4 Genetic differentiation $\left(\mathrm{F}_{\mathrm{ST}}\right)$ and gene flow $(\mathrm{Nm})$ based on COI, 16S rRNA and COI + 16S rRNA sequences of $R$. microplus populations in Malaysia

\begin{tabular}{lllll}
\hline Population 1 & Population 2 & COI & 16S rRNA & COI + 16S rRNA \\
\hline B & C & 0.0474 & 0.0524 & 0.0483 \\
B & D & 0.1477 & 0.0833 & 0.1468 \\
B & G & 0.0220 & 0.0400 & 0.0226 \\
B & H & 0.0510 & 0.0777 & 0.0522 \\
C & D & 0.1344 & 0.0000 & 0.1334 \\
C & G & 0.0146 & 0.0000 & 0.0143 \\
C & H & 0.0565 & 0.0361 & 0.0558 \\
D & G & -0.1067 & 0.0000 & -0.1057 \\
D & H & 0.0091 & 0.0690 & 0.0095 \\
G & H & -0.0778 & 0.0259 & -0.0758 \\
& Nm & 36.92 & 12.47 & 35.59
\end{tabular}

This study also identified distinct haplotype clusters as shown by a mixture of several genetically divergent groups in the Malaysian tick populations (Fig. 2). The significant genetic differentiation and high gene flow rates among the sampling sites support genetic admixture. The relatively low yet significant genetic differentiation and the widespread genetic admixture detected here were consistent with genetic studies of $R$. microplus populations from southern Texas [14]. This previous study proposed that southern Texas $R$. microplus has been introduced on multiple occasions, and these introductions have been associated with two main dispersal mechanisms (i.e., frequent

Table 3 Percentage of uncorrected " $p$ " distance matrix among the 18 representative COI + 16S rRNA haplotypes of R. microplus in Malaysia

\begin{tabular}{|c|c|c|c|c|c|c|c|c|c|c|c|c|c|c|c|c|c|c|}
\hline & $\mathrm{H} 1$ & $\mathrm{H} 2$ & $\mathrm{H} 3$ & $\mathrm{H} 4$ & $\mathrm{H} 5$ & $\mathrm{H} 6$ & $\mathrm{H} 7$ & $\mathrm{H} 8$ & $\mathrm{H} 9$ & $\mathrm{H} 10$ & $\mathrm{H} 11$ & $\mathrm{H} 12$ & $\mathrm{H} 13$ & $\mathrm{H} 14$ & $\mathrm{H} 15$ & $\mathrm{H} 16$ & $\mathrm{H} 17$ & $\mathrm{H} 18$ \\
\hline $\mathrm{H} 1$ & - & & & & & & & & & & & & & & & & & \\
\hline $\mathrm{H} 2$ & 0.10 & - & & & & & & & & & & & & & & & & \\
\hline H3 & 2.34 & 2.44 & - & & & & & & & & & & & & & & & \\
\hline $\mathrm{H} 4$ & 4.88 & 4.98 & 2.83 & - & & & & & & & & & & & & & & \\
\hline H5 & 4.79 & 4.88 & 2.93 & 0.10 & - & & & & & & & & & & & & & \\
\hline H6 & 5.18 & 5.27 & 3.13 & 0.49 & 0.59 & - & & & & & & & & & & & & \\
\hline $\mathrm{H7}$ & 4.98 & 5.08 & 2.83 & 0.39 & 0.49 & 0.68 & - & & & & & & & & & & & \\
\hline $\mathrm{H} 8$ & 0.10 & 0.20 & 2.44 & 4.98 & 4.88 & 5.27 & 5.08 & - & & & & & & & & & & \\
\hline H9 & 0.20 & 0.29 & 2.54 & 4.89 & 4.79 & 5.18 & 4.98 & 0.10 & - & & & & & & & & & \\
\hline $\mathrm{H} 10$ & 0.20 & 0.29 & 2.54 & 4.88 & 4.79 & 5.18 & 4.98 & 0.29 & 0.20 & - & & & & & & & & \\
\hline $\mathrm{H} 11$ & 0.20 & 0.29 & 2.54 & 4.88 & 4.79 & 5.18 & 4.98 & 0.29 & 0.20 & 0.20 & - & & & & & & & \\
\hline $\mathrm{H} 12$ & 0.10 & 0.20 & 2.44 & 4.79 & 4.69 & 5.08 & 4.88 & 0.20 & 0.10 & 0.10 & 0.10 & - & & & & & & \\
\hline $\mathrm{H} 13$ & 0.10 & 0.20 & 2.44 & 4.98 & 4.88 & 5.27 & 5.08 & 0.20 & 0.29 & 0.29 & 0.29 & 0.20 & - & & & & & \\
\hline $\mathrm{H} 14$ & 1.37 & 1.46 & 3.32 & 5.47 & 5.37 & 5.76 & 5.57 & 1.46 & 1.56 & 1.56 & 1.56 & 1.46 & 1.46 & - & & & & \\
\hline $\mathrm{H} 15$ & 0.88 & 0.98 & 2.83 & 4.98 & 4.88 & 5.27 & 5.08 & 0.98 & 1.08 & 1.07 & 1.07 & 0.98 & 0.98 & 0.68 & - & & & \\
\hline $\mathrm{H} 16$ & 0.39 & 0.49 & 2.73 & 5.27 & 5.18 & 5.57 & 5.37 & 0.49 & 0.59 & 0.59 & 0.59 & 0.49 & 0.49 & 1.56 & 1.07 & - & & \\
\hline $\mathrm{H} 17$ & 0.29 & 0.39 & 2.64 & 5.18 & 5.08 & 5.47 & 5.27 & 0.39 & 0.49 & 0.49 & 0.49 & 0.39 & 0.39 & 1.46 & 0.98 & 0.10 & - & \\
\hline $\mathrm{H} 18$ & 0.39 & 0.49 & 2.64 & 5.18 & 5.08 & 5.27 & 5.27 & 0.49 & 0.59 & 0.59 & 0.59 & 0.49 & 0.49 & 1.56 & 1.07 & 0.39 & 0.29 & - \\
\hline
\end{tabular}




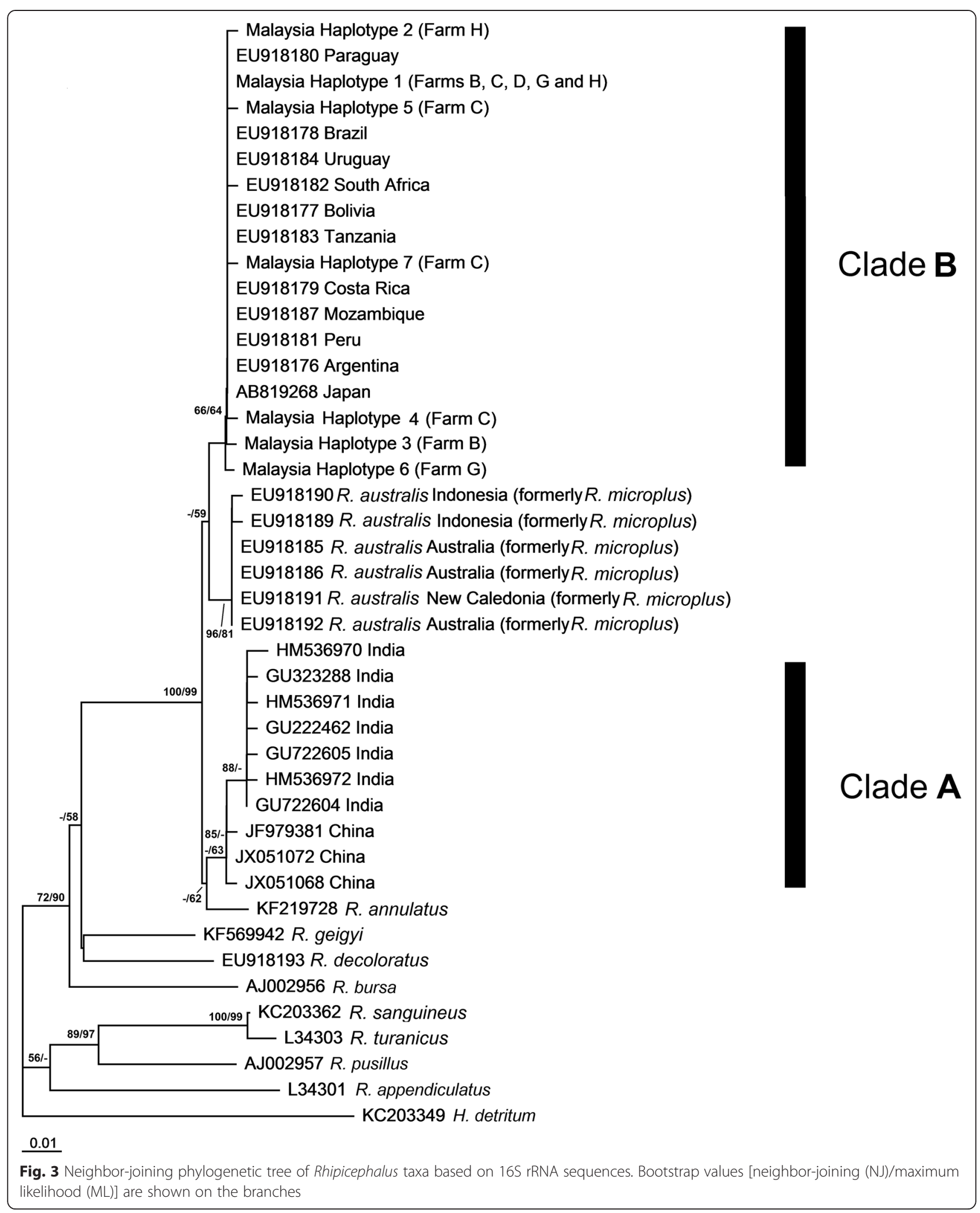

short-distance dispersal and rare long-distance, humanmediated dispersal), thus promoting genetic admixture among tick populations. Additionally, the highly invasive and widespread movement of $R$. microplus [14, 36, 37] may facilitate its occurrence and observed high levels of gene flow. The studied cattle farms owned by the DVS in 


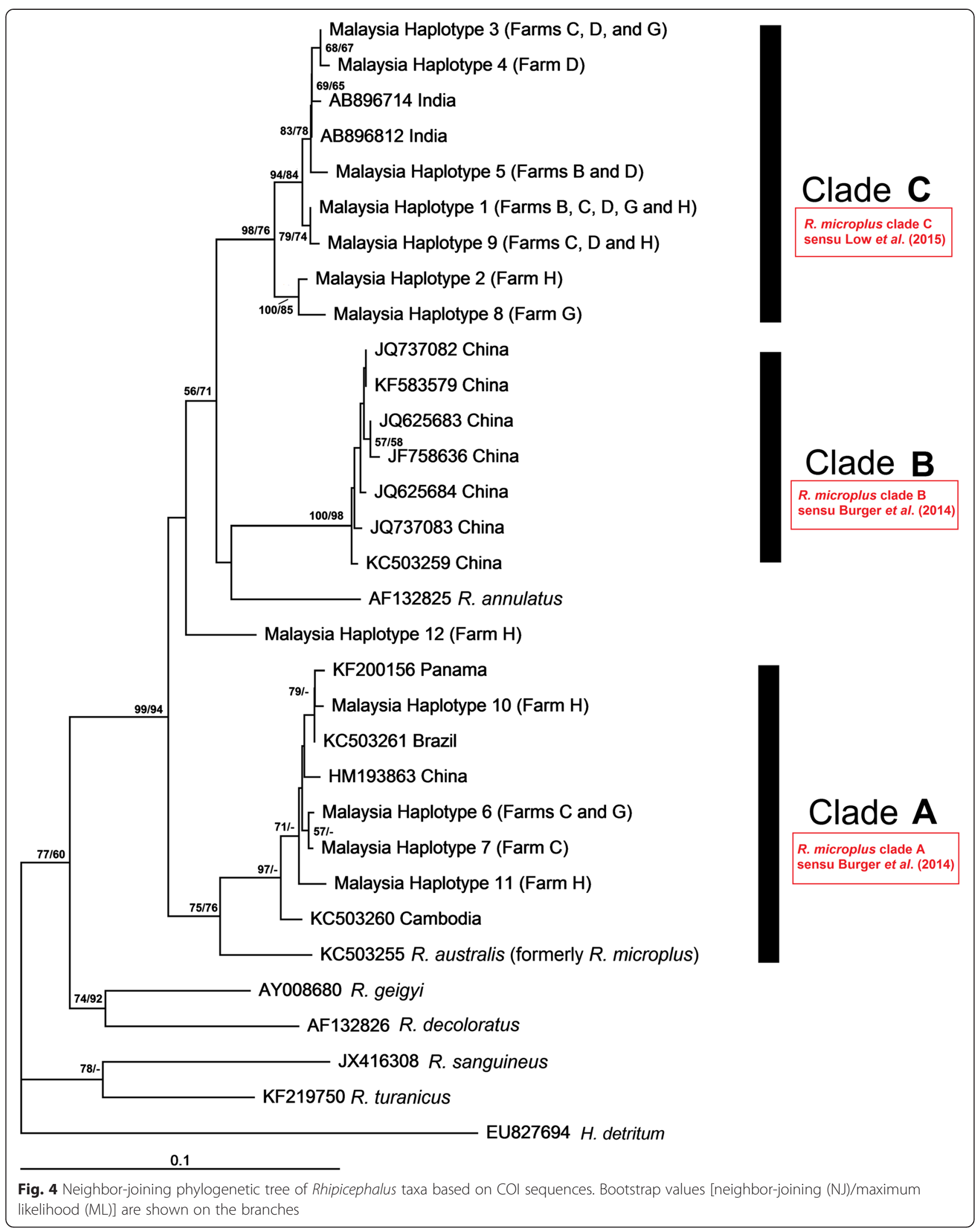


Malaysia serve as the sources of cattle production for imported and local breeds and eventually distribute the animals to all private farms throughout Malaysia. The natural dispersal ability of ticks might occur in parallel with human-mediated dispersal, causing genetic admixture and high gene flow in Malaysian populations.

Morever, this study also attempted to investigate whether haplotypes are distributed according to cattle breed. The specific association of haplotypes with other cattle breeds was not obvious except for some ticks collected from the Nellore breed which was imported from India. A distinct haplotype cluster (H16, H17, H18) was found for R. microplus ticks collected from these cattle. It is unknown whether this indicates a cause-effect association of haplotypes and this cattle breed. However, the prevalence of ticks has been typically associated with cattle breeds [38-40].

Over the last decade, a number of molecular approaches have been adopted to infer the phylogeographical relationships of $R$. microplus populations from different parts of the world [11-16]. As far as the molecular approaches are concerned, the mitochondria-encoded $16 \mathrm{~S}$ rRNA and COI genes have invariably unraveled the distinct genetic assemblages of $R$. microplus and differentiated its closely related species, $R$. annulatus and $R$. australis $[10,15,16]$. Here, our $16 \mathrm{~S}$ rRNA data were consistent with previous studies in which two $16 \mathrm{~S}$ rRNA genetic clades were detected, with the first clade primarily confined to Africa/the Americas and the second clade confined to China/India. In contrast to the results found with the 16S rRNA gene, the COI phylogenetic data provided a new insight into the evolutionary lineages of $R$. microplus with the identification of three main assemblages: clade A sensu Burger et al. (2014), comprising ticks from Southeast Asia, the Americas and China; clade B sensu Burger et al. (2014), restricted to ticks that originated from China; and clade $\mathrm{C}$ sensu Low et al. (2015) , a new genetic assemblage discovered in this study, comprising ticks from India and Malaysia. Notably, the Chinese and Indian ticks were separated into different clades, in contrast to the 16S rRNA data. These results have unraveled the hidden diversity of Indian ticks, providing evidence that at least two distinct assemblages, namely $R$ microplus clade A sensu Burger et al. (2014) and $R$ microplus clade $C$ sensu Low et al. (2015) exist in India. However, the majority of the COI haplotypes (seven out of 12) found in Malaysian ticks are shared with ticks from India. A plausible explanation for this could be because of the consequences of intense commercial cattle trade between both countries.

The comparative analysis in this study shows that $R$. microplus ticks represent at least three distinct genetic assemblages. Additional consideration should be given to the geographical differences between ticks in Malaysia and those from India, China and the Americas. Seasonal variations (e.g., temperature, climate and humidity) among the countries could be factors that shaped the observed patterns of genetic structure. Moreover, the role of anthropogenic disturbances in structuring the current genetic variability of $R$. microplus cannot be ruled out. This tick has been deemed the 'world's most pesticide-resistant tick' and the evolution of biotypes with resistance to at least 44 active ingredients has been documented worldwide [41]. Hence, the ticks might have experienced selection pressure from pesticides leading to the observed high genetic variability. Additionally, because speciation might be driven by ecological divergence, the cryptic diversity of $R$. microplus might be underestimated. The recent study of Burger et al. [10] has suggested the presence of cryptic species in $R$. microplus, complicates the assessment of species status and is a common challenge in the Ixodidae. In this regard, crossbreeding studies from different isolates of $R$. microplus, including the new taxon $R$. microplus clade C sensu Low et al. (2015) discovered in the present study should be conducted in the near future.

\section{Conclusions}

This study provides new insights into the distinct genetic assemblages in the tick $R$. microplus. We, therefore, conclude that the $R$. microplus complex consisting of at least five taxa: $R$. australis, $R$. annulatus, $R$. microplus clade A sensu Burger et al. (2014), R. microplus clade B sensu Burger et al. (2014) and the new taxon, $R$. microplus clade $C$ sensu Low et al. (2015). The use of COI as the standard genetic marker in discerning the genetic assemblages of $R$. microplus from a broad range of biogeographical regions is proposed.

\section{Additional file}

Additional file 1: Figure S1. Sequence alignment of $R$. microplus

haplotypes ( $\mathrm{H} 1-\mathrm{H} 18)$ based on $\mathrm{COI}+16 \mathrm{~S}$ rRNA genes.

\section{Competing interests}

The authors declare that they have no competing interests.

\section{Authors' contributions}

VLL, STT and MSA conceived the research in collaboration with KLK, FXK, TKT, YALL, BLO, CP and YNR. VLL, KLK, FXK and TKT collected the specimens. VLL, KLK, FXK and TKT conducted the experiments. VLL and TKT performed the sequence analyses. VLL wrote the paper. All authors have read and approved the manuscript.

\section{Acknowledgements}

The authors would like to thank Dato' Dr. Quaza Nizamuddin Hassan Nizam, Director, Department of Veterinary Services (DVS), Ministry of Agriculture and Agro-Based Industry, Malaysia for granting approval of tick collection from

the farms that participated in this study. Our appreciation is also extended to Dato' Dr. Ibrahim Che Embung, Dr. Tariq Jaafar, Dr. Arman bin Kison, Mr. Chang Kum Wah and Mr. Salleh Sheikh Ibrahimfrom DVS for the coordination, assistance and support given to this study. We would like to acknowledge the assistance and cooperation provided by the managers and workers of each farm. This project was funded by the University of Malaya research grants (RP003C-13SUS, RP013-2012A and E and PV085-2011A). 


\section{Author details}

${ }^{1}$ Institute of Biological Sciences, Faculty of Science, University of Malaya, Kuala Lumpur, Malaysia. ${ }^{2}$ Department of Medical Microbiology, Faculty of Medicine, University of Malaya, Kuala Lumpur, Malaysia. ${ }^{3}$ Department of Parasitology, Faculty of Medicine, University of Malaya, Kuala Lumpur, Malaysia. ${ }^{4}$ Faculty of Veterinary Medicine, Universiti Malaysia Kelantan, Kota Bharu, Kelantan, Malaysia. ${ }^{5}$ Veterinary Research Institute, Ipoh, Perak, Malaysia.

Received: 1 May 2015 Accepted: 16 June 2015

Published online: 24 June 2015

\section{References}

1. Suarez CE, Noh S. Emerging perspectives in the research of bovine babesiosis and anaplasmosis. Vet Parasitol. 2011;180(1-2):109-25.

2. Chen Z, Liu Q, Liu JQ, Xu BL, Lv S, Xia S, et al. Tick-borne pathogens and associated co-infections in ticks collected from domestic animals in central China. Parasit Vector. 2014;7:237.

3. Yssouf A, Socolovschi C, Kernif T, Temmam S, Lagadec E, Tortosa P, et al. First molecular detection of Rickettsia africae in ticks from the Union of the Comoros. Parasit Vector. 2014;7:444.

4. Costa VM, Ribeiro MF, Duarte AL, Mangueira JM, Pessoa AF, Azevedo SS, et al. Seroprevalence and risk factors for cattle anaplasmosis, babesiosis, and trypanosomiasis in a Brazilian semiarid region. Rev Bras Parasitol Vet. 2013;22(2):201-13.

5. Dantas-Torres F, Chomel BB, Otranto D. Ticks and tick-borne diseases: a One Health perspective. Trends Parasitol. 2012;28(10):437-46.

6. Jabbar A, Abbas T, Sandhu ZD, Saddiqi HA, Qamar MF, Gasser RB. Tickborne diseases of bovines in Pakistan: major scope for future research and improved control. Parasit Vector. 2015;8:283.

7. Yu Z, Wang H, Wang T, Sun W, Yang X, Liu J. Tick-borne pathogens and the vector potential of ticks in China. Parasit Vector. 2015;8:24.

8. Lew-Tabor AE, Bruyeres AG, Zhang B, Valle MR. Rhipicephalus (Boophilus) microplus tick in vitro feeding methods for functional (dsRNA) and vaccine candidate (antibody) screening. Ticks Tick Borne Dis. 2014;5(5):500-10.

9. Barker SC, Walker AR. Ticks of Australia. The species that infest domestic animals and humans. Zootaxa. 2014;3816:1-144.

10. Burger TD, Shao R, Barker SC. Phylogenetic analysis of mitochondrial genome sequences indicates that the cattle tick, Rhipicephalus (Boophilus) microplus, contains a cryptic species. Mol Phylogenet Evol. 2014;76:241-53.

11. Hernandez R, Chen AC, Davey RB, Ivie GW, Wagner GG, George JE. Comparison of genomic DNA in various strains of Boophilus microplus (Acari: Ixodidae). J Med Entomol. 1998;35(5):895-900.

12. Passos DT, Ferreira CA, da Silva SS, Richter MF, Ozaki LS. Detection of genomic variability in different populations of the cattle tick Boophilus microplus in southern Brazil. Vet Parasitol. 1999:87(1):83-92.

13. Chigagure NN, Baxter GD, Barker SC. Microsatellite loci of the cattle tick Boophilus microplus (Acari: Ixodidae). Exp Appl Acarol. 2000;24(12):951-6.

14. Busch JD, Stone NE, Nottingham R, Araya-Anchetta A, Lewis J, Hochhalter C, et al. Widespread movement of invasive cattle fever ticks (Rhipicephalus microplus) in southern Texas leads to shared local infestations on cattle and deer. Parasit Vector. 2014;7:188

15. Labruna MB, Naranjo V, Mangold AJ, Thompson C, Estrada-Peña A, Guglielmone AA, et al. Allopatric speciation in ticks: genetic and reproductive divergence between geographic strains of Rhipicephalus (Boophilus) microplus. BMC Evol Biol. 2009;9:46.

16. Estrada-Peña A, Venzal JM, Nava S, Mangold A, Guglielmone AA, Labruna MB, et al. Reinstatement of Rhipicephalus (Boophilus) australis (Acari: Ixodidae) with redescription of the adult and larval stages. J Med Entomol. 2012;49(4):794-802.

17. Hedin MC. Molecular phylogenetics at the population/species interface in cave spiders of the Southern Appalachians (Araneae: Nesticidae: Nesticus). Mol Bio Evol. 1997;14(3):309-24.

18. Mtambo J, Madder M, Van Bortel W, Geysen D, Berkvens D, Backeljau T. Genetic variation in Rhipicephalus appendiculatus (Acari: Ixodidae) from Zambia: correlating genetic and ecological variation with Rhipicephalus appendiculatus from eastern and southern Africa. J Vector Ecol. 2007:32(2):168-75

19. Walker AR, Bouattour A, Camicas JL. Ticks of Domestic Animals in Africa: A Guide to Identification of Species. Scotland: The University of Edinburgh; 2003.
20. Lv J, Wu S, Zhang Y, Zhang T, Feng C, Jia G, et al. Development of a DNA barcoding system for the Ixodida (Acari: Ixodida). Mitochondrial DNA. 2014;25(2):142-9

21. Shao R, Campbell NJ, Barker SC. Numerous gene rearrangements in the mitochondrial genome of the wallaby louse, Heterodoxus macropus (Phthiraptera). Mol Biol Evol. 2001;18(5):858-65.

22. Chitimia L, Lin RQ, Cosoroaba I, Wu XY, Song HQ, Yuan ZG, et al. Genetic characterization of ticks from southwestern Romania by sequences of mitochondrial cox1 and nad5 genes. Exp Appl Acarol. 2010;52(3):305-11.

23. LV J, Wu S, Zhang Y, Chen Y, Feng C, Yuan X, et al. Assessment of four DNA fragments (COI, 16S rDNA, ITS2, 12S rDNA) for species identification of the Ixodida (Acari: Ixodida). Parasit Vector. 2014;7:93.

24. Hall TA. BioEdit: a user-friendly biological sequence alignment editor and analysis program for Windows 95/98/NT. Nucleic Acids Symp Ser. 1999:41:95-8.

25. Swofford DL. PAUP: Phylogenetic Analysis using Parsimony (and other methods) Version 4. Sunderland, Massachusetts: Sinauer Associates; 2002

26. Huson DH, Bryant D. Application of phylogenetic networks in evolutionary studies. Mol Bio Evol. 2006:23(2):254-67.

27. Librado P, Rozas J. DnaSP v5: a software for comprehensive analysis of DNA polymorphism data. Bioinformatics. 2009;25(11):1451-2.

28. Wright S. Evolution and the Genetics of Populations. Vol. 4, Variability within and Among Natural Populations. Chicago: University of Chicago Press; 1978.

29. Govindajuru RD. Variation in gene flow levels among predominantly selfpollinated plants. J Evol Biol. 1989;2(3):173-81.

30. Saitou N, Nei M. The neighbor-joining method: a new method for reconstructing phylogenetic trees. Mol Biol Evol. 1987;4(4):406-25.

31. Tamura K, Peterson D, Peterson N, Stecher G, Nei M, Kumar S. MEGA5: Molecular evolutionary genetics analysis using maximum likelihood, evolutionary distance, and maximum parsimony methods. Mol Biol Evol. 2011:28(10):2731-9.

32. Kimura M. A simple method for estimating evolutionary rate of base substitutions through comparative studies of nucleotide sequences. J Mol Evol. 1980;16(2):111-20

33. Guindon S, Dufayard JF, Lefort V, Anisimova M, Hordijk W, Gascuel O. New algorithms and methods to estimate maximum-likelihood phylogenies: assessing the performance of PhyML 3.0. Syst Biol. 2010:59(3):307-21.

34. Dantas-Torres F, Latrofa MS, Annoscia G, Giannelli A, Parisi A, Otranto D. Morphological and genetic diversity of Rhipicephalus sanguineus sensu lato from the New and Old Worlds. Parasit Vector. 2013;23:213.

35. Latrofa MS, Dantas-Torres F, Annoscia G, Cantacessi C, Otranto D. Comparative analyses of mitochondrial and nuclear genetic markers for the molecular identification of Rhipicephalus spp. Infect Genet Evol. 2013;20:422-7.

36. Lewis IJ. Observations on the dispersal of larvae of the cattle tick Boophilus microplus (Can.). Bull Entomol Res. 1970;59(4):595-604.

37. Madder M. Rhipicephalus (Boophilus) microplus: a most successful invasive tick species in West-Africa. Exp Appl Acarol. 2011;53(2):139-45.

38. Yacob HT, Ataklty H, Kumsa B. Major ectoparasites of cattle in and around Mekelle, northern Ethiopia. Entomol Res. 2008;38(2):126-30.

39. Jawale CS, Dama LB, Dama SB. Prevalence of Ixodid ticks in post acaricide treated cattle and buffaloes at Sinner District Nashik (M.S) India. Trends in. Parasitol Res. 2012;1(1):20-4.

40. Ibelli AM, Ribeiro AR, Giglioti R, Regitano LC, Alencar MM, Chagas ACS, et al. Resistance of cattle of various genetic groups to the tick Rhipicephalus microplus and the relationship with coat traits. Vet Parasitol. 2012;186(3-4):425-30.

41. Arthropod Pesticide Resistance Database Available: http:// www.pesticideresistance.com. Accessed 30 April, 2015. 